\title{
Blue-Red Tuning Emission of Zn0: Europium Quantum Dots with Different Excitation Wavelengths
}

\author{
Primitivo Ortiz Maldonado, Ana K. Chavez-Alvarado², Francisco J. Rodríguez Gutierrez², \\ Joan Reyes Miranda2 ${ }^{2}$, Dulce Y. Medina Velazquez², Miguel A. Barron², Elizabeth Garfias García² \\ ${ }^{1}$ Universidad Autónoma Intercultural de Sinaloa, El Fuerte, México \\ ${ }^{2}$ División de Ciencias Básicas e Ingeniería, Universidad Autónoma Metropolitana, Reynosa Tamaulipas, México \\ Email: bmma@correo.azc.uam.mx
}

How to cite this paper: Maldonado, P.O., Chavez-Alvarado, A.K., Gutierrez, F.J.R., Miranda, J.R., Velazquez, D.Y.M., Barron, M.A. and García, E.G. (2018) Blue-Red Tuning Emission of $\mathrm{ZnO}$ : Europium Quantum Dots with Different Excitation Wavelength. Open Journal of Applied Sciences, 8, 441-445.

https://doi.org/10.4236/ojapps.2018.810034

Received: September 11, 2018

Accepted: October 9, 2018

Published: October 12, 2018

Copyright ( $\odot 2018$ by authors and Scientific Research Publishing Inc. This work is licensed under the Creative Commons Attribution International License (CC BY 4.0).

http://creativecommons.org/licenses/by/4.0/

(c) (i) Open Access

\begin{abstract}
Optoelectronic applications require the development of new fluorescent and efficient luminescent materials, free of toxicity, low in cost, and easy to produce. In this way the synthesis of zinc-oxide $(\mathrm{ZnO})$ quantum dots (QDs) has recently received special attention due to their good optical, electrical and chemical properties with low production costs and blue light emission. In this work $\mathrm{ZnO}$ QDs were successfully doped with europium in order to obtain a tunable emission luminescence from blue emission of $\mathrm{ZnO}$ to red emission of europium as a function of wavelength excitation. Results show an efficient blue to red tuning when the excitation wavelength was changed from $317 \mathrm{~nm}$ to $395 \mathrm{~nm}$, respectively. This opens the possibility of having new optical devices to produce different color emission using the same material.
\end{abstract}

\section{Keywords}

Chromaticity Diagram, Emission Spectra, Europium Luminescence, Red-Blue Tuning, ZnO Quantum Dots, White Light

\section{Introduction}

Quantum dots (QDs) are crystalline particles nanometer-sized composed of lanthanide semiconductors which have highly efficient optical properties. QDs have many applications due to their strong and stable fluorescence with tunable light emission and absorption. Their main applications are efficient lighting, photovoltaic energy, and training of biological images [1]. On the other hand, 
ZnO QD has high quantum yield, quantum size effects, broad absorption and narrow emission spectrum. $\mathrm{ZnO}$ QDs are environmental friendly, nontoxic, less expensive, and biocompatible compared to traditional QDs semiconductors such as $\mathrm{CdS}, \mathrm{CdTe}$, and CdSe [2] [3] [4]. Besides, $\mathrm{ZnO}$ is a wide and direct band-gap n type $(3.37 \mathrm{eV})$ semiconductor, and shows a large exciton binding energy of $60 \mathrm{meV}$ [5]-[12] which has recently attracted considerable interest for applications in optical and optoelectronic devices such as blue light-emitting diodes covering the absorption of the entire ultraviolet range. Moreover, the $\mathrm{ZnO}$ QDs exhibit a hydrophilic character since they show great stability in water without a decrease in their luminescent properties. In a recent paper, it is reported that the incorporation of $\mathrm{ZnO}$ QDs enhance the optical performance of the grating [7].

Different methods have been proposed to the synthesis of $\mathrm{ZnO}$ QDs, like radio frequency magnetron sputtering, molecular-beam epitaxy, pulsed laser deposition, chemical-vapor deposition and sol-gel process [13] [14]. The sol-gel method has been proposed, since presents several advantages like: high purity, ultra-homogeneity, low processing temperature and the possibility to incorporate lanthanide ions into an oxide host. In this regard, the red light emission of $\mathrm{Eu}^{3+}$ lanthanide ions are well known when they are used as light activators of ZnO QDs.

In this regard, the present work reports a photoluminescence study of europium-doped $\mathrm{ZnO}$ QDs as possible tunable material from blue emission arising from the $\mathrm{ZnO}$ host to the red emission coming from $\mathrm{Eu}^{3+}$ ions by exciting at different wavelengths (317 - $395 \mathrm{~nm}$ ). The results show different emission spectra when the wavelength excitation was changed in order to analyze the emission of de $\mathrm{ZnO}$ and Europium ions for different intensity ratios.

\section{Experimental}

\subsection{QDs Preparation}

For the preparation of $\mathrm{ZnO}$ nanoparticles doped with europium (Eu), europium chloride $\left(\mathrm{EuCl}_{3}\right)$ and zinc acetate $\left(\mathrm{Zn}\left(\mathrm{C}_{4} \mathrm{H}_{6} \mathrm{O}_{4}\right)\right)$ were chosen as precursors. As solvents, methanol $\left(\mathrm{CH}_{3} \mathrm{OH}\right)$ and glycerol $\left(\mathrm{C}_{3} \mathrm{H}_{8} \mathrm{O}_{3}\right)$ were used. Acetic acid $\left(\mathrm{CH}_{3} \mathrm{COOH}\right)$ was employed as modifier, and distilled water was used for washing.

The synthesis of the sample consisted of mixing and dissolving $0.164 \mathrm{~g}$ of zinc acetate (98\% Sigma Aldrich), $0.05 \mathrm{~g}$ of europium chloride (99.9\% Sigma Aldrich), $2.5 \mathrm{~g}$ of glycerol and $2 \mathrm{~g}$ of methanol. Then, the sample was heated to $120^{\circ} \mathrm{C}$ under vigorous stirring and the colloidal solution was kept at that temperature for $1 \mathrm{~h}$. During the process, at $30 \mathrm{~min}$ the solution took a yellow color and around $45 \mathrm{~min}$ the nanoparticles began to nucleate and grow, taking a white color in short time. After $1 \mathrm{~h}, 100 \mu \mathrm{l}$ of acetic acid was added in order to evaporate the highest amount of solvents used in the synthesis and until the final obtainment of $5 \mathrm{ml}$ of colloidal solution. The $\mathrm{ZnO}$ nanoparticles exhibited a hydrophilic character since they showed great stability in water without a decrease 
in their luminescent properties. In a recent paper, it is reported that the incorporation of $\mathrm{ZnO}$ QDs enhance the optical performance of the grating [7].

\subsection{Photoluminescence Characterization}

Photoluminescence spectra were recorded by means of a Horiba Jobin Yvon Fluorolog Spectrofluorometer equipped with a $150 \mathrm{~W}$ ozone-free Xenon lamp for the steady state mode. All the measurements were carried out at room temperature.

\section{Results and Discussion}

\section{Photoluminescence Emission Spectra}

Figure 1 shows the emission luminescence characterization. As the wavelength excitation was increased the emission of $\mathrm{ZnO}$ was changed from $405 \mathrm{~nm}$ to $450 \mathrm{~nm}$. One interesting feature presented is that at $405 \mathrm{~nm}$ the transition of Europium ions is diminished. When the wavelength was increased to $392 \mathrm{~nm}$ the transition of Europium ions is highly increased, and the maximum emission was obtained at $395 \mathrm{~nm}$ of excitation wavelength, showing that the $\mathrm{ZnO}$ emission is singly decreased for an energy transfer process. Europium presented the characteristic transitions ${ }^{5} \mathrm{D}_{0} \rightarrow{ }^{7} \mathrm{~F}_{1},{ }^{5} \mathrm{D}_{0} \rightarrow{ }^{7} \mathrm{~F}_{2}$ and ${ }^{5} \mathrm{D}_{0} \rightarrow{ }^{7} \mathrm{~F}_{3}$.

Figure 2 shows the CIE (Commission Internationale de lÉclairage) chromaticity diagram at different wavelengths of excitation. It can be appreciated that the emission color moves from blue to red as the wavelength excitation changes from 317, 320, 392, 393 and $395 \mathrm{~nm}$. This is because the $\mathrm{ZnO}$ emission moves from $405 \mathrm{~nm}$ to $450 \mathrm{~nm}$ and also because the emission intensity of europium was increased. These results confirm the tunable color of the emission when the wavelength is changed.

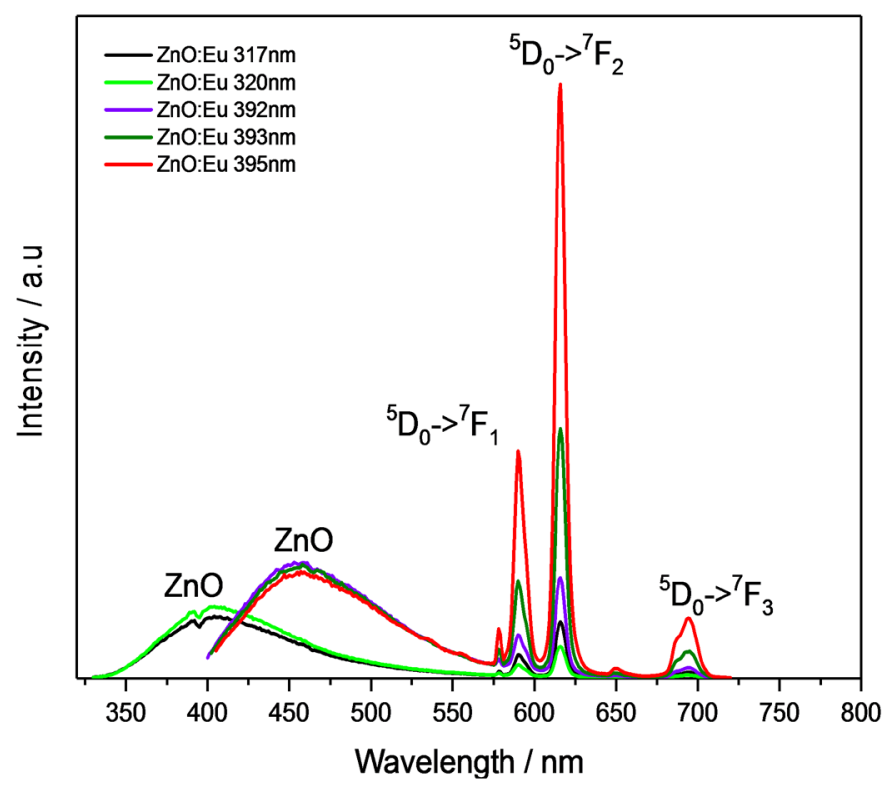

Figure 1. Emission spectra of $\mathrm{ZnO}$ :Eu QDs at different wavelengths of excitation. 


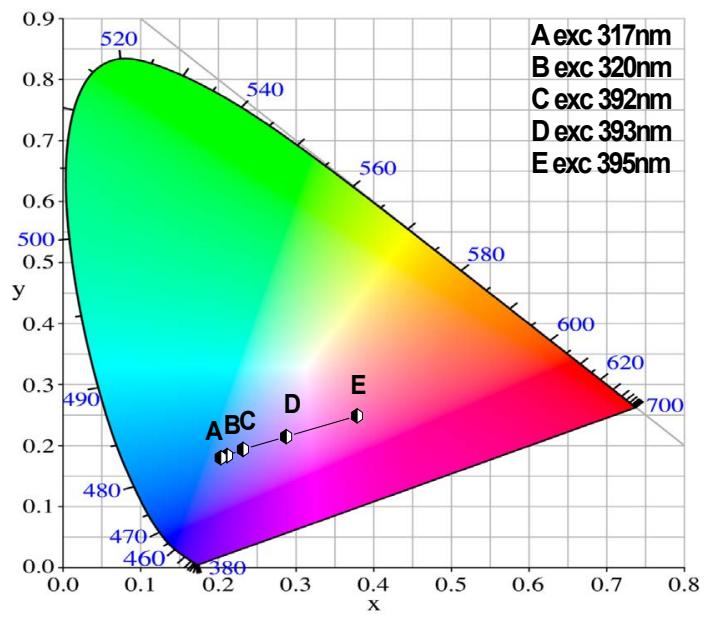

Figure 2. CIE chromaticity diagram of the emission color at different wavelengths of excitation.

\section{Conclusion}

The synthesis of europium doped zinc oxide quantum dots were successfully carried out. The broad blue emission centered at $405 \mathrm{~nm}$ arising from $\mathrm{ZnO}$ host is recorded at a wavelength excitation of 317 and $320 \mathrm{~nm}$, while the characteristic transition of $\mathrm{Eu}^{3+}$ ions $\left({ }^{5} \mathrm{D}_{0} \rightarrow{ }^{7} \mathrm{~F}_{2}\right)$ was low compared to the $\mathrm{ZnO}$ emission. However, the excitation at $392 \mathrm{~nm}$ changes the emission of the $\mathrm{ZnO}$ host at $455 \mathrm{~nm}$ and the emission of $\mathrm{Eu}^{3+}$ is lightly increased. Finally, the occurrence of a highly emission of $\mathrm{Eu}^{3+}$ ions is recorded by exciting at 393 and $395 \mathrm{~nm}$. This last result allows tuning the color emission from blue to red.

\section{Acknowledgements}

This work was supported by the Consejo Nacional de Ciencia y Tecnología (CONACyT) Project No. 254280. Primitivo Ortiz thanks to UAIS for the supported to finish his bachelor and make this research project, and thanks to all the professors of Quality System Engineering of UAIS for the supported.

\section{Conflicts of Interest}

The authors declare no conflicts of interest regarding the publication of this paper.

\section{References}

[1] Monticone, S., Tufeu, R. and Kanaev, A.V. (1998) Complex Nature of the UV and Visible Fluorescence of Colloidal ZnO Nanoparticles. Journal of Physical Chemistry $B, 102,2854-2862$. https://doi.org/10.1021/jp973425p

[2] Xiao, J.B., Zhao, Y.R., Mao, F.F., Liu, J., Wu, M.X. and Yu, X.B. (2012) Investigation of the Toxic Effect of a QDs Heterojunction on the Interactions between Small Molecules and Plasma Proteins by Fluorescence and Resonance Light-Scattering Spectra. Analyst, 137, 195-201. https://doi.org/10.1039/C1AN15457E

[3] Jana, N.R., Yu, H.H., Ali, E.M., Zheng, Y.G. and Ying, J.Y. (2007) Controlled Pho- 
tostability of Luminescent Nanocrystalline ZnO Solution for Selective Detection of Aldehydes. Chemical Communications, 1406-1408. https://doi.org/10.1039/b613043g

[4] Xiong, H.M., Xu, Y., Ren, Q.G. and Xia, Y.Y. (2008) Stable Aqueous ZnO@Polymer Core-Shell Nanoparticles with Tunable Photoluminescence and Their Application in Cell Imaging. Journal of the American Chemical Society, 130, 7522-7523. https://doi.org/10.1021/ja800999u

[5] Mari, B., Mollar, M., Mechkour, A., Hartiti, B., Perales, M. and Cembrero, J. (2004) Optical Properties of Nanocolumnar ZnO Crystals. Microelectronics Journal, 35, 79-82. https://doi.org/10.1016/S0026-2692(03)00227-1

[6] Chander, R. and Raychaudhuri, A.K. (2008) Electrodeposition of Aligned Arrays of $\mathrm{ZnO}$ Nanorods in Aqueous Solution. Solid State Communications, 145, 81-85. https://doi.org/10.1016/j.ssc.2007.09.031

[7] Vanpoucke, D.E.P. (2014) Comment on "Europium Doping Induced Symmetry Deviation and Its Impact on the Second Harmonic Generation of Doped ZnO Nanowire”. Nanotechnology, 25, Article ID: 458001. https://doi.org/10.1088/0957-4484/25/45/458001

[8] Zhong, W.W., Guan, D.W., Liu, Y.L., Zhang, L., Liu, Y.P., Li, Z.G. and Chen, W.P. (2012) Effect of Annealing on the Structure and Photoluminescence of Eu-Doped $\mathrm{ZnO}$ Nanorods Ordered Array Thin Films. Journal of Nanomaterials, 2012, Article ID: 263679. https://doi.org/10.1155/2012/263679

[9] Zeng, H., Duan, G., Li, Y., Yang, S., Xu, X. and Cai, W. (2010) Blue Luminescence of $\mathrm{ZnO}$ Nano-Particles Based on Non-Equilibrium Processes: Defect Origins and Emission Controls. Advanced Functional Materials, 20, 561-572. https://doi.org/10.1002/adfm.200901884

[10] Goourey, G.G., Claire, P.S., Balan, L. and Israeli, Y. (2013) Acrylate Photopolymer Doped with $\mathrm{ZnO}$ Nanoparticles: An Interesting Candidate for Photo-Patterning Applications. Journal of Materials Chemistry C, 1, 3430-438. https://doi.org/10.1039/c3tc30263f

[11] Sil, D. and Chakrabarti, S. (2010) Photocatalytic Degradation of PVC-ZnO Composite Film under Tropical Sunlight and Artificial UV Radiation: A Comparative Study. Solar Energy, 84, 476-485. https://doi.org/10.1016/j.solener.2009.09.012

[12] Ellmer, K., Klein, A. and Rech, B. (2007) Transparent Conductive Zinc Oxide: Basics and Applications in Thin Film Solar Cells. Springer Series in Materials Science, Springer, Berlin, Heidelberg.

[13] Ozgur, O., Alivov, Y.I., Liu, C., Teke, A., Reshchikov, M., Dogan, S., Avrutin, V., Cho, S.J. and Morkoc, H. (2005) A Comprehensive Review of $\mathrm{ZnO}$ Materials and Devices. Journal of Applied Physics, 98, 11. https://doi.org/10.1063/1.1992666

[14] Natsume, Y. and Sakata, H. (2002) Electrical and Optical Properties of Zinc Oxide Films Post-Annealed in $\mathrm{H}_{2}$ after Fabrication by Sol-Gel Process. Materials Chemistry and Physics, 78, 170-176. https://doi.org/10.1016/S0254-0584(02)00314-0 